Research Paper

\title{
Mono- and heterofunctionalized silica magnetic microparticles (SMMPs) as new carriers for immobilization of lipases
}

\author{
Lionete Nunes de Lima ${ }^{a}$, Gustavo Nakamura Alves Vieira ${ }^{\mathrm{b}}$, Willian Kopp ${ }^{\mathrm{a}, \mathrm{c}}$, \\ Paulo Waldir Tardioli ${ }^{\mathrm{a}, *}$, Raquel L.C. Giordano ${ }^{\mathrm{a}}$ \\ a Graduate Program in Chemical Engineering, Department of Chemical Engineering, Federal University of São Carlos, Rodovia Washington Luiz, km 235, \\ 13565-905 São Carlos, SP, Brazil \\ ${ }^{\mathrm{b}}$ Department of Biochemistry and Chemical Technology, Institute of Chemistry, UNESP - São Paulo State University, Araraquara, SP, Brazil \\ ${ }^{\mathrm{c}}$ Kopp Technologies (KTech), Rua Alfredo Lopes, 1717, Jardim Macarengo, 13560-460 São Carlos, SP, Brazil
}

\section{A R T I C L E I N F O}

\section{Article history:}

Received 29 October 2016

Received in revised form 5 April 2017

Accepted 5 April 2017

Available online 6 April 2017

\section{Keywords:}

Silica magnetic microparticles

Heterofunctionalization

Candida antarctica lipase B

Xylose fatty acid ester

\begin{abstract}
A B S T R A C T
In order to improve economic viability of an enzymatic process, the use of an operationally stable and low-cost biocatalyst is encouraged. Although the immobilization of lipases is widely reported, the search for new supports and immobilization protocols with better properties is still important. In this study, mono- and heterofunctionalized silica magnetic microparticles (SMMPs) were synthetized for immobilization of lipase B from Candida antarctica (CALB). The SMMPs were prepared in a micro-emulsion system containing sodium silicate and superparamagnetic iron oxide nanoparticles, followed by chemical modification with octyl groups and octyl plus aldehyde groups. These supports allowed the immobilization of CALB by hydrophobic adsorption or hydrophobic/covalent linkages, achieving immobilization yield of $88 \%$ and recovered activities of $128 \%$ and $59 \%$, respectively. The performance of the magnetic biocatalysts was evaluated in the synthesis of xylose fatty acid esters (laurate or oleate) in tert-butyl alcohol medium, yielding around $60 \%$ conversion after $48 \mathrm{~h}$ under optimized conditions (xylose/fatty acid molar ratio of $1: 0.2,55^{\circ} \mathrm{C}$, and activity load of $37.5 \mathrm{U} / \mathrm{g}$ ). The magnetic biocatalyst was used in 10 reaction cycles of $48 \mathrm{~h}$ at $46^{\circ} \mathrm{C}$ maintaining high xylose conversions. Besides, the biocatalyst might be easily and quickly recovered from the reaction medium by an external magnetic field, an operational advantage in the case of viscous and complex media, e.g., medium containing insoluble sugars and molecular sieves.
\end{abstract}

(c) 2017 Elsevier B.V. All rights reserved.

\section{Introduction}

Most of the enzymes, including lipases for synthesis in organic medium, have their stability and reusability improved by immobilization onto solid supports [1-3]. Although several immobilized lipases are commercially available (e.g., Novozym 435, Amano lipase PS, etc.), the search for new functionalized solid supports and immobilization protocols with better properties is still important. Recently, magnetic particles (e.g., silica magnetic particles) have been reported as carrier for immobilization of some lipases (e.g., lipase from Pseudomonas cepacia, Thermomyces lanuginosus, and Pseudomonas fluorescens) to be used in the synthesis of esters

\footnotetext{
* Corresponding author at: Departamento de Engenharia Química, Universidade Federal de São Carlos, Rodovia Washington Luiz, km 235, 13565-905, São Carlos, SP, Brazil.

E-mail addresses: pwtardioli@hotmail.com, pwtardioli@ufscar.br (P.W. Tardioli).
}

[4-6]. The use of magnetic particles is encouraged due to the fact that they can be easily and quickly separated from the reaction medium by applying an external magnetic field, facilitating the separation of the biocatalyst even in complex and viscous reaction medium. In this context, this work aimed at the synthesis and characterization of a new superparamagnetic biocatalyst, obtained by immobilization of lipase B from Candida antarctica (CALB) on silica magnetic microparticles (SMMPs) mono- or heterofuncionalized with octyl or octyl plus aldehyde groups. The performance of the biocatalysts was evaluated in the synthesis of xylose fatty acid esters in tert-butyl alcohol medium.

Sugar fatty acid esters (SFAEs) are non-toxic, biodegradable and non-ionic amphiphilic molecules obtained by the acylation of one or more hydroxyl groups of a carbohydrate (commonly mono- or disaccharides), using a fatty acid as acyl donor. The emulsifying properties of SFAEs allow their use in many commercial products and processes, like in the pharmaceutical and food industries [7]. Besides, some SFAEs present antimicrobial activity against common pathogens that cause food poisoning and spoilage [8,9]. 
Although SFAEs derived from fructose, glucose or sucrose are synthesized in industrial scale by transesterification of methyl esters in the presence of alkaline or metallic catalysts, the reaction conditions are severe (temperature close to $100^{\circ} \mathrm{C}$ ), the selectivity is low, and by-products (such as methanol) are toxic [7]. The enzymatic route can overcome these drawbacks. Different acyl acceptors have been used to synthesize SFAEs via enzymatic catalysis [10-12]. Among the carbohydrates that have been used to produce SFAEs, xylose has been sparsely used as acyl acceptor [13-16], but it may be an interesting choice, considering that the xylan-rich stream from the lignocellulosic pretreatment aiming to produce $2 \mathrm{G}$-ethanol is an underused by-product.

\section{Materials and methods}

\subsection{Materials}

Immobilized lipase B from Candida antarctica (CALB IM - T2350) was acquired from Chiral Vision (Leiden, Netherlands). This enzyme is covalently attached on acrylic resin activated with epoxy groups (Immobead $\left.{ }^{\mathrm{TM}} 150 / 350-P\right)$. Soluble lipase B from Candida antarctica (CALB), molecular sieve UOP type $3 \AA$ (rod-shaped, size $1 / 16$ in), tetrahydrated iron (II) chloride $\left(\mathrm{FeCl}_{2} \cdot 4 \mathrm{H}_{2} \mathrm{O}\right)$, hexahydrated iron (III) chloride $\left(\mathrm{FeCl}_{3} \cdot 6 \mathrm{H}_{2} \mathrm{O}\right)$, triethoxy(octyl)silane (OCTES), triethoxy(3-aminopropyl)silane (APTES), triton X-100 (TX), tributyrin 97\% were acquired from Sigma Aldrich Co. (St. Louis, MO, USA). Ammonium sulfate $\left(\left(\mathrm{NH}_{4}\right)_{2} \mathrm{SO}_{4}\right)$ was acquired from $\mathrm{J}$. T. Baker (New Jersey, USA). Tert-butyl alcohol, xylose, sodium silicate $\left(\mathrm{Na}_{2} \mathrm{SiO}_{3}\right)$ and lauric acid were acquired from Vetec (Rio de Janeiro, Brazil). Toluene, cyclohexane, ammonium hydroxide and oleic acid were acquired from Synth (São Paulo, Brazil). Hexane and acetone were acquired from Qhemis (São Paulo, Brazil). All the other reagents were of analytical grade.

\subsection{Methods}

\subsubsection{Synthesis of mono- and heterofunctionalized SMMPS}

The magnetic support was synthesized in a core-shell structure, i.e., an iron oxide magnetic core coated with a silica shell. The silica shell was chemically modified (as described below), allowing different immobilization methods.

2.2.1.1. Synthesis of the magnetic iron core. The iron oxide magnetic nanoparticles (core) were synthesized according to Kopp et al. [6]. Two iron aqueous solutions $\left(350 \mathrm{mM} \mathrm{FeCl}{ }_{3} \cdot 6 \mathrm{H}_{2} \mathrm{O}\right.$ and $200 \mathrm{mM}$ $\mathrm{FeCl}_{2} \cdot 4 \mathrm{H}_{2} \mathrm{O}$ ) were prepared separately and then mixed together $\left(200 \mathrm{~mL}\right.$ of each) in a jacketed reactor at $60^{\circ} \mathrm{C}$ under mechanical stirring (1000 rpm). Afterwards, $50 \mathrm{~mL}$ of $\mathrm{NH}_{4} \mathrm{OH}$ solution (28 wt.\%) was added in the reactor and the reaction was carried out for $1 \mathrm{~h}$. The iron oxide magnetic nanoparticles were recovered using a magnet, washed with distilled water and stored until use.

2.2.1.2. Porous silica coating. The magnetic core was coated with porous silica according to Kopp et al. [6], yielding silica magnetic microparticles (SMMPs). Two solutions were prepared separately as following: solution A was prepared by adding $40 \mathrm{~mL}$ of $1.75 \mathrm{M}$ $\mathrm{Na}_{2} \mathrm{SiO}_{3}$ solution in $140 \mathrm{~mL}$ of cyclohexane containing $20 \mathrm{~mL}$ of Triton $\mathrm{X}-100$, and solution $\mathrm{B}$ was prepared by adding $40 \mathrm{~mL}$ of $1 \mathrm{M}$ $\left(\mathrm{NH}_{4}\right)_{2} \mathrm{SO}_{4}$ solution in $140 \mathrm{~mL}$ of cyclohexane containing $20 \mathrm{~mL}$ of Triton X-100. Thereafter, $15 \mathrm{~g}$ of iron oxide magnetic nanoparticles was added to the solution $\mathrm{A}$, which was stirred forming a stable emulsion. Solution B was then slowly added and the mixture was kept at $25^{\circ} \mathrm{C}$ for $1 \mathrm{~h}$ under $1000 \mathrm{rpm}$ mechanical stirring. The support (SMMPs) was washed with distilled water and incubated in
$0.1 \mathrm{M} \mathrm{HCl}$ for $1 \mathrm{~h}$ under stirring. The SMMPs was finally washed until neutral $\mathrm{pH}$ and dried at $60^{\circ} \mathrm{C}$ for $12 \mathrm{~h}$.

2.2.1.3. Surface activation of the SMMPs. the functionalization of SMMPs with octyl groups (SMMP-octyl) was carried out using OCTES as following: $1 \mathrm{~g}$ of SMMPs was suspended in $25 \mathrm{~mL}$ of toluene containing $1 \mathrm{mmol}$ of OCTES. The suspension was kept under reflux for $5 \mathrm{~h}$, filtered under vacuum, and the SMMP-octyl particles were washed with acetone and distilled water, followed by drying at $60^{\circ} \mathrm{C}$ [6]. The heterofunctionalization of SMMPs with octyl plus glutaraldehyde groups (SMMP-octyl-glu) was carried out using OCTES and APTES, according an adaptation of the methodology described by Vescovi et al. [1]: $1 \mathrm{~g}$ of SMMPs was suspended in $25 \mathrm{~mL}$ of toluene containing $1.5 \mathrm{mmol}$ of OCTES and $0.5 \mathrm{mmol}$ of APTES, in order to add amino groups to the support. The suspension was kept under reflux for $5 \mathrm{~h}$, filtered under vacuum, and the SMMP-octyl-amino particles were washed with acetone and distilled water, followed by drying. The activation with aldehyde groups was carried out according an adaptation of the methodology described by Vescovi et al. [1] as following: $1 \mathrm{~g}$ of dried SMMP-octyl-amino particles was added to $10 \mathrm{~mL}$ of $25 \%(\mathrm{v} / \mathrm{v})$ glutaraldehyde solution. The suspension was kept under stirring for $1 \mathrm{~h}$ at room temperature, filtered under vacuum, and the activated support (SMMP-octyl-glu) was washed with distilled water.

2.2.1.4. Characterization of the SMMPs. The morphology of the SMMPs and the octyl coated SMMPs was investigated using a Philips XL30 FEG microscopy operating at $25 \mathrm{kV}$. Aqueous suspensions containing SMMPs were deposited onto an aluminum sample holder, dried at room temperature and gold-coated. The scanning electron microscopy (SEM) images were recorded at distinct magnifications. The particle diameter distribution (Feret's diameter) was estimated by image analysis using the ImageJ software. The energy dispersive X-ray spectroscopy (EDS) was performed in the same equipment using an Oxford Tetra Link detector. Nitrogen adsorption-desorption isotherms were performed using an ASAP 2010 (Micrometrics). Isotherm results, in the appropriate ranges, were used for surface area and pore diameter calculations via the Brunauer-Emmett-Teller - BET and Barrett-Joyner- Halenda - BJH equations, respectively.

\subsubsection{Immobilization of lipase $B$ from Candida antarctica}

The immobilization of CALB was carried out according to the protocol adapted from Blanco et al. [17]. One gram of the support (SMMP-octyl for hydrophobic adsorption or SMMP-octyl-glu for hydrophobic adsorption plus covalent linkage) was added to $2 \mathrm{~mL}$ of ethanol. The suspension was kept at $25^{\circ} \mathrm{C}$ under mild agitation for one hour. Afterwards, $18 \mathrm{~mL}$ of the enzymatic solution (prepared in sodium phosphate solution $100 \mathrm{mM}, \mathrm{pH} 7.0$ ) was added to the suspension. Enzymatic loads of 5 and $20 \mathrm{mg}$ protein/g support were evaluated.

The enzyme immobilization was monitored by measurement of the hydrolytic activity $\left(U_{H}\right)$ in the supernatant solution, and also monitoring the activity of an enzyme solution incubated at the same conditions (control solution). The immobilization yield (IY) was calculated from Equation (1):

$I Y=\frac{U_{H 0}-U_{H f}}{U_{H 0}} 100 \%$

In Eq. (1), $\mathrm{U}_{\mathrm{HO}}$ is the initial hydrolytic activity of the supernatant solution and $\mathrm{U}_{\mathrm{Hf}}$ is the final hydrolytic activity of the supernatant solution, both expressed in $\mathrm{U} / \mathrm{mL}$.

Recovered activity (RA) was calculated from Eq. (2):

$R A=\frac{U_{E d} m_{S}}{U_{E S} V_{E S} I Y} 100 \%$ 
Table 1

Coded variables of the factorial design of experiments.

\begin{tabular}{llllll}
\hline Variable & -1.68 & -1 & 0 & 1 & 1.68 \\
\hline Temperature $\left({ }^{\circ} \mathrm{C}\right)$ & 37 & 40.6 & 46 & 51.3 & 55 \\
Acid/xylose molar ratio & $1: 3$ & $1: 1.66$ & $1: 1$ & $1: 0.72$ & $1: 0.59$ \\
Enzymatic load $\left(\mathrm{U}_{\mathrm{E}} / \mathrm{g}_{\text {acid }}\right)$ & 25 & 30.1 & 37.5 & 44.9 & 50 \\
\hline
\end{tabular}

In Eq. (2), $U_{E d}$ is the esterification activity of the derivative (in terms of $U_{E d} / g$ of biocatalyst), $m_{S}$ is the mass of support (expressed in $g$ ), $U_{E s}$ is the esterification activity of the enzyme solution (in terms of $\mathrm{U}_{\mathrm{Es}} / \mathrm{mL}$ ), and $\mathrm{V}_{\mathrm{Es}}$ is the volume of the enzyme solution (expressed in $\mathrm{mL}$ ) used in the immobilization.

Recovered activity was calculated based on esterification activity because CALB immobilized on functionalized SMMPs showed to be not suitable to hydrolyze tributyrin, probably due to the high hydrophobicity of the supports that could have delayed the tributyrin transfer from the bulk to the internal pore structure of the biocatalyst.

\subsubsection{Lipase activities}

2.2.3.1. Hydrolytic activity. The hydrolytic activity of the enzymatic preparations was determined by the method of tributyrin hydrolysis, according to protocol adapted from Beisson et al. [18]. A tributyrin solution was prepared by mixing $5 \mathrm{~mL}$ of $100 \mathrm{mM}$ sodium phosphate buffer, $13 \mathrm{~mL}$ of distilled water, and $2 \mathrm{~mL}$ of tributyrin. The solution was kept under stirring at $40^{\circ} \mathrm{C}$ and an enzyme solution $(100 \mu \mathrm{L})$ was added to initiate the reaction. The released butyric acid was titrated with $0.1 \mathrm{M} \mathrm{KOH}$ in a Titrino 718 automatic titrator (Metrohm) in order to maintain the $\mathrm{pH}$ of the reaction medium at 7.5. One unit of hydrolytic activity $\left(U_{H}\right)$ was defined as the amount of enzyme which releases $1 \mathrm{mM}$ of butyric acid per minute, at the assay conditions.

2.2.3.2. Esterification activity. The esterification activity of the biocatalysts based on the synthesis of butyl butyrate was measured by the method described by Paula et al. [19]. A volume of $10 \mathrm{~mL}$ of substrate ( $0.1 \mathrm{M} 1$-butanol and $0.1 \mathrm{M}$ butyric acid in heptane) was kept at $37^{\circ} \mathrm{C}$ under $300 \mathrm{rpm}$ stirring. A volume of $200 \mu \mathrm{L}$ of the soluble enzyme or $200 \mathrm{mg}$ of the derivative was added to the reaction medium. Samples were withdrawn at predefined time intervals to quantify 1-butanol consumption by gas chromatography in a 7890A GC Agilent, equipped with FID detector, using a HP-Innowax column $(30 \mathrm{~m}, 0.32 \mathrm{~mm}, 0.25 \mu \mathrm{m})$, with heating rate of $30^{\circ} \mathrm{C} / \mathrm{min}$ from 100 to $200^{\circ} \mathrm{C}$. The sample volume injected into the column was $1 \mu \mathrm{L}$, using nitrogen as carrier, at a feed rate of $1 \mathrm{~mL} / \mathrm{min}$.

One unit of esterification activity $\left(U_{E}\right)$ was defined as the rate of formation of $1 \mathrm{mM}$ of butyl butyrate per minute at the assay conditions.

\subsubsection{Synthesis of xylose fatty acid esters}

The syntheses of xylose fatty acid esters were carried out by esterification of oleic acid or lauric acid with xylose, using tert-butyl alcohol as solvent, in a batch reactor. The operational variables evaluated in this work were temperature, fatty acid/xylose molar ratio, and enzymatic load $\left(U_{E} / g\right.$ of fatty acid). A factorial design of experiments was used to analyze the influence of the variables on xylose conversion after $48 \mathrm{~h}$ reaction, with three replicates on the central point. The levels of the variables and their codes are shown in Table 1.

The experiments related to this design were carried out for both derivatives (CALB-SMMP-octyl and CALB-SMMP-octyl-glu) and for the commercial immobilized Candida antarctica lipase B (CALB IM). The software Statistica was used to perform analyses of variances (ANOVAs) of the results of the factorial design and to obtain regression models to describe mathematically the response vari- able (xylose conversion after $48 \mathrm{~h}$ ) as a function of the operational variables. Charts which show the statistical influence of the parameters of a linear regression model were used for the description of the response variable obtained, (i.e. the Pareto charts were obtained after data analysis). Response surfaces based on these analyses were also obtained, considering the statistically significant coefficients (at a $95 \%$ confidence interval).

One gram of molecular sieves was used in all experiments. The concentration of fatty acid was fixed as $20 \mathrm{mM}$ in all the experiments, hence different levels of fatty acid/xylose molar ratio corresponded to different initial xylose concentrations. Similarly, different levels of enzymatic load corresponded to different masses of the biocatalysts.

A fixed volume was sampled from the reaction medium and dried at $80^{\circ} \mathrm{C}$ for $14 \mathrm{~h}$ to remove the solvent. The remaining solid (which contained the product and xylose) was then dissolved in the same volume of water to solubilize the non-converted xylose. Then, xylose concentration was measured by high efficiency liquid chromatography (HPLC), in a Waters chromatograph equipped with a refractive index detector, using a Shodex KS802 column at $80^{\circ} \mathrm{C}$, using Milli-Q water as mobile phase and injected sample volume of $1 \mu \mathrm{L}$. Conversion was calculated from the decrease in the xylose concentration, using a xylose calibration curve as reference.

Additional experiments were carried out at temperature and enzymatic load correspondent to the central point $\left(46^{\circ} \mathrm{C}\right.$ and $37.5 \mathrm{U}_{\mathrm{E}} / \mathrm{g}$ ). However, different xylose concentrations were used (fatty acid/xylose molar ratio of 1:0.2, 1:0.14 and 1:0.1). As discussed below, the reason for these experiments was the fact that lower xylose concentrations yielded higher conversions.

The experiment which yielded the highest conversion $\left(37.5 \mathrm{U}_{\mathrm{E}} / \mathrm{g}\right.$, at 46 and $55^{\circ} \mathrm{C}$ and fatty acid/xylose molar ratio of 1:0.2) was repeated, in order to quantify xylose consumption as a function of reaction time.

\subsubsection{Operational stability (Reuse assay)}

The derivatives CALB-SMMP-octyl, CALB-SMMP-octyl-glu and CALB IM were used in ten $48 \mathrm{~h}$-cycles of syntheses of xylose oleate and xylose laurate at $46^{\circ} \mathrm{C}$ in $10 \mathrm{~mL}$ of tert-butyl alcohol as solvent, under $300 \mathrm{rpm}$ mechanical stirring. Fatty acid/xylose molar ratio of $1: 0.2,20 \mathrm{mM}$ fatty acid, $1 \mathrm{~g}$ of molecular sieves, and activity load of $37.5 \mathrm{U}_{\mathrm{E}} / \mathrm{g}$ of fatty acid were used. After each $48 \mathrm{~h}$ reaction cycle, the biocatalyst was washed with hexane and reused in a new reaction cycle under the same conditions. The conversion of xylose was calculated by measurements of xylose by HPLC method as described above.

\section{Results and discussion}

\subsection{Characterization of the SMMPS}

SMMPs were produced and their surface modified using OCTES resulting in a new material containing octyl groups on its surface. The hydrophobic SMMP-octyl was analyzed by SEM images (Fig. 1). It is possible to observe that both, the SMMP and the SMMPoctyl particles present irregular shape and micrometric size with a short particle size distribution. The micro-structure of the materials was very similar to that observed by Kopp et al. [6]. The SMMP surface (Fig. 1B) presents a pore structure formed by small particles of nanometric size; these fundamental particles are magnetic nanoparticles covered with a silica layer [6]. The SMMP-octyl surface, in turn, presents a more uniform surface with some blocked pores (Fig. 1D); this can be an effect of the surface modification with octyl groups. The SMMP-octyl particle size distribution was calculated by image analysis using SEM images (Fig. 1S, Supplementary data). The analysis confirms that the SMMP-octyl presents 

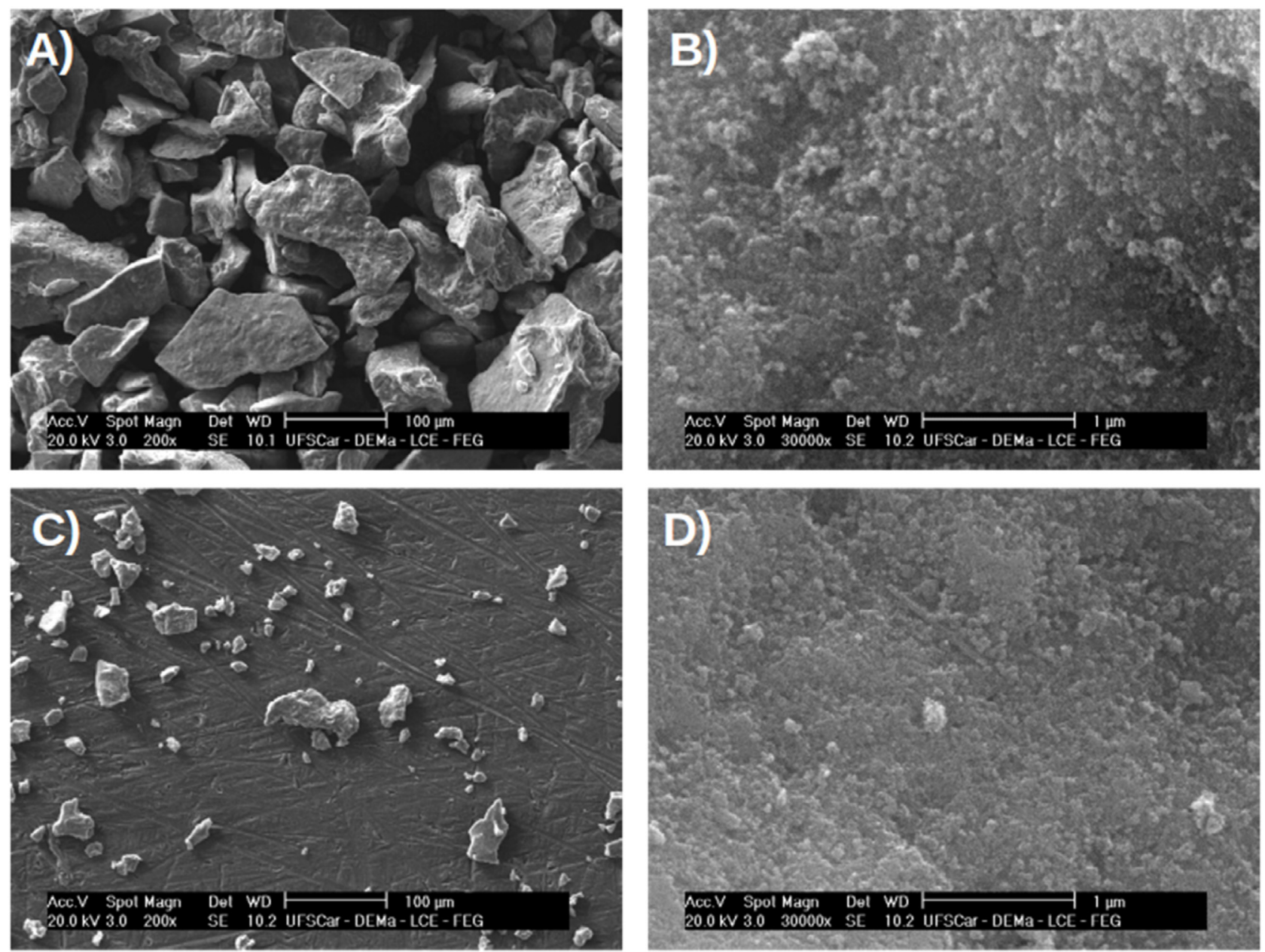

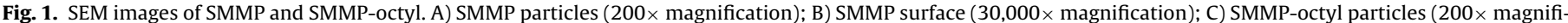
cation); D) SMMP-octyl surface (30,000 $\times$ magnification).

a short particle size distribution with most of the particles between 10 and $20 \mu \mathrm{m}$, but with some bigger particles $(>50 \mu \mathrm{m})$. This profile of particle size distribution is highly adequate to enzymes immobilization, avoiding decrease in enzymes activity caused by mass transfer effects.

The elemental composition of SMMP and SMMP-octyl were evaluated by EDS analysis, showing the following concentration of elements (\%): for SMMP - Fe (49.83), Si (8.34), O (41.83), and C (0), and for SMMP-octyl - Fe (50.29), Si (10.31), O (37.22), and C (2.18).

As expected, both samples present a high concentration of iron from the magnetic nanoparticles and a moderate concentration of silicon from the silica layer. This balance of a high concentration of magnetic cores with a very thin layer of silica allows obtaining a material with high magnetic response [6]. The surface modification of SMMP with OCTES increased the silica content in the SMMPoctyl; in this sample was possible to detect approximately $2 \%$ of carbon, confirming the surface modification with octyl groups.

Fig. 2 S-A (Supplementary data) shows the nitrogen adsorptiondesorption isotherm of the SMMP sample. The isotherm observed is an IUPAC type IV, assigned to mesoporous solids. However, the curve also shows some features of type II and III isotherms assigned to nonporous solids. These results can be explained by the fact that the sample contains mixed phases of porous silica and nonporous iron oxide nanoparticles. The porous size distribution (Fig. 2S-B, Supplementary data) showed that SMMP has large pore size distribution, containing mesoporous and macroporous [6]. The surface area calculated for SMMP was $148 \mathrm{~m}^{2} / \mathrm{g}$ (BET method) and the average pore size was $13.5 \mathrm{~nm}$ (BJH method). These features make the SMMP and the SMMP-octyl suitable to be used as carriers for immobilization of enzymes.

\subsection{CALB immobilization}

Fig. 2 shows the tributyrin hydrolytic activity in the supernatant $v s$. immobilization time of CALB on SMMP-octyl and SMMP-octylglu supports.

Activity of the control solution (soluble enzyme at the immobilization conditions) shows that the soluble enzyme did not inactivate under the immobilization conditions $\left(25^{\circ} \mathrm{C}, \mathrm{pH} 7.0\right)$. Hence the decrease of activity in the supernatant can be associated to the immobilization of the enzyme on the supports. The immobilization of CALB on SMMP-octyl in the presence of ethanol was faster than in its absence, as previously reported for CALB immobilization on silica coated with octyl groups [17]. Ethanol did not influence significantly the immobilization of CALB on SMMP-octylglu, suggesting that the mechanism of immobilization of CALB on this support was mainly by covalent interaction between very reactive glutaraldehyde moieties on the support surface and reactive nucleophiles on the enzyme surface, mainly deprotonated amino groups [1].

Table 2 shows the immobilization yields and the recovered activities of both magnetic biocatalysts. Immobilization yields were high for all supports (above 87\%), however, the highest recovered activities were obtained for CALB immobilized on SMMPs 


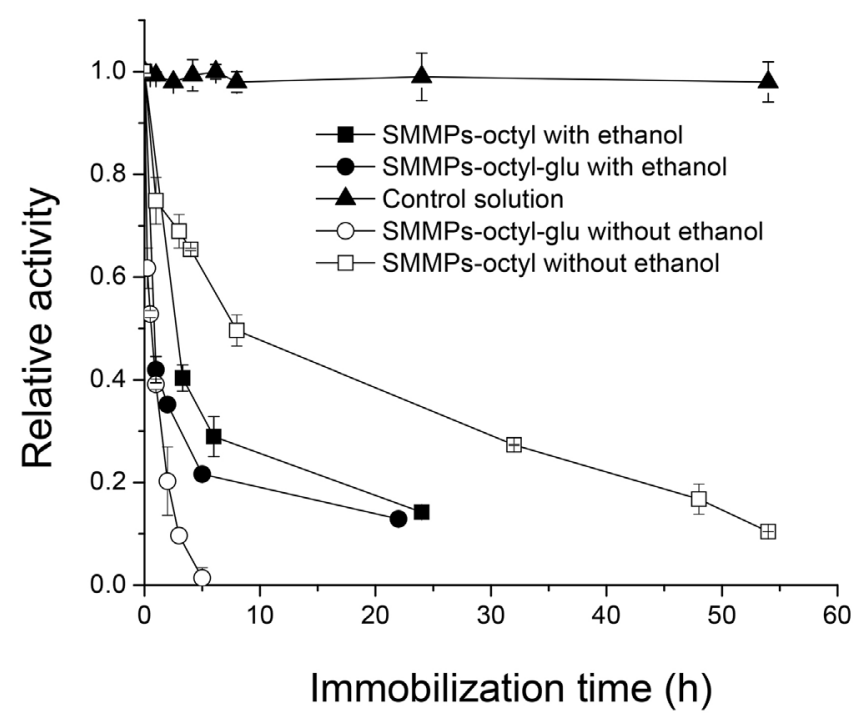

Fig. 2. Tributyrin hydrolysis activity in the supernatant solution as a function of the immobilization time of CALB on SMMP-octyl (squares) and SMMP-octyl-glu (circles) at $25^{\circ} \mathrm{C}, \mathrm{pH} 7.0$ ( $100 \mathrm{mM}$ sodium phosphate buffer solution), and enzymatic loading of $5 \mathrm{mg} / \mathrm{g}$. Control solution (triangles) shows that soluble CALB did not inactive at the immobilization conditions.

Table 2

Parameters of immobilization of CALB on SMMP-octyl and SMMP-octyl-glu at $25^{\circ} \mathrm{C}, \mathrm{pH} 7.0$ ( $100 \mathrm{mM}$ sodium phosphate buffer). Enzymatic loading $5 \mathrm{mg}$ protein/g support.

\begin{tabular}{llll}
\hline Support & Ethanol & IY $(\%)$ & RA (\%) \\
\hline CALB-SMMP-octyl & $(+)$ & $86.7 \pm 1.5$ & $128.2 \pm 2.3$ \\
CALB-SMMP-octyl-glu & $(+)$ & $88.3 \pm 1.9$ & $59.2 \pm 6.4$ \\
CALB-SMMP-octyl & $(-)$ & $89.6 \pm 0.0$ & $50.2 \pm 4.5$ \\
CALB-SMMP-octyl-glu & $(-)$ & $95.2 \pm 1.3$ & $33.5 \pm 2.6$ \\
\hline
\end{tabular}

a Calculated by esterification activity; $(+)$ presence of ethanol; $(-)$ absence of ethanol.

supports in the presence of ethanol, 59.2 and 128.2\% for SMMPoctyl-glu and SMMP-octyl supports, respectively. The difference for the recovered activities could be explained by the catalytic mechanism of lipases, which undergoes conformational changes in its structure in the presence of hydrophobic surfaces (e.g., oil drops, air bubbles, hydrophobic supports, etc.), increasing its catalytic properties [17]. The addition of ethanol also slightly increases hydrophobicity of the support, and decrease the protein solubility in the support microenvironment which also affects positively the immobilization by hydrophobic adsorption. The highly hydrophobic SMMP-octyl could have favored the enzyme coupling (slow, as shown in Fig. 2) in its active form, while the SMMP-octyl-glu, less hydrophobic, favored the quick enzyme coupling by its deprotonated amino groups with the enzyme structure in its native form. Besides, the covalent linkage enzyme-support could impair large conformational changes in the enzyme structure required to the catalysis, decreasing its catalytic activity. Furthermore, some deleterious effect of the glutaraldehyde not could be discarded, such as, loss of activity due to distorted change in the tertiary structure of the enzyme or active site blockage [20]. Kopp et al. [6] also reported hyperactivation and high immobilization yield for the immobilization of lipase from Pseudomonas fluorescens onto silica magnetic microparticles (SMMPs) coated with octyl groups (163\% recovered activity and $77.5 \%$ immobilization yield). The hydrophobic nature of the octyl coated SMMPs favored the opening of the lipase's lid increasing its lipolytic activity. Therefore, octyl coated SMMPs compared with previous works are very suitable for immobilization/hyperactivation of lipases. Kalantari et al. [4] reported the immobilization of lipase from Pseudomonas cepacia onto magnetic
Table 3

Activities of immobilized CALB at $37^{\circ} \mathrm{C}$ in the esterification of 1-butanol and butyric acid $(0.1 \mathrm{M})$ in heptane.

\begin{tabular}{llll}
\hline Biocatalysts & IY, \% & \multicolumn{2}{l}{ Esterification activity } \\
\cline { 3 - 4 } & & $\left(\mathrm{U}_{\mathrm{E}} / \mathrm{g}\right.$ support $)$ & $\left(\mathrm{U}_{\mathrm{E}} /\right.$ mg protein $^{\mathrm{a}}$ \\
\hline CALB IM & $\mathrm{n} / \mathrm{a}$ & $54.0 \pm 2.3$ & $\mathrm{n} / \mathrm{a}$ \\
CALB-SMMP-octyl & $52.3 \pm 4.0$ & $21.8 \pm 0.1$ & $2.1 \pm 0.0$ \\
CALB-SMMP-octyl-glu & $59.6 \pm 4.2$ & $19.7 \pm 2.0$ & $1.7 \pm 0.2$
\end{tabular}

a Calculated considering the protein immobilized on the SMMP-octyl (10.5 mg) and SMMP-octyl-glu (11.9 mg): offered load $(20 \mathrm{mg} / \mathrm{g}$ support $) \times$ IY.

silica particles to be used in the synthesis of biodiesel. The immobilization yields and recovered activities ranged from 49 to $62 \%$ and from 87 to $91 \%$, respectively, depending on the silica pore structure (non-porous, mesoporous or macroporous) and its resulting diffusional delays. Khoobi et al. [5] reported the adsorption of Thermomyces lanuginosus lipase on polyethyleneimine or succinated polyethyleneimine grafted onto silica coated magnetic particles to be used as biocatalyst in the synthesis of ethyl valerate (an aroma ester). The biocatalysts showed recovered activities ranging from 22 to $34 \%$.

\subsection{Esterification activity}

Table 3 shows the esterification activities for commercial immobilized CALB and derivatives prepared in this work in presence of ethanol, offering to the supports the load of $20 \mathrm{mg}$ protein $/ \mathrm{g}$. Activities of the biocatalysts CALB-SMMP-octyl and CALB-SMMPoctyl-glu were similar, although recovered activities were different for those biocatalysts. This difference indicates mass transfer delays into the internal surface of the biocatalyst, very common for highloaded biocatalysts $[1,2,4,21]$.

The esterification activity per gram of the commercial immobilized CALB was around 2.5-fold higher in comparison to the activities of the derivatives prepared in this work. Since the enzymatic load of the commercial biocatalyst is not known, a direct comparison between the biocatalysts is not feasible. In addition, because of its iron oxide magnetic core the SMMPs present a higher density in comparison with the commercial acrylic resin of the CALB IM derivative core [6], which hinders a direct comparison between the derivatives based only in the mass of the materials. The highest density of the CALB immobilized on SMMPs allows the reactor to be loaded with high enzyme activity, occupying less useful volume, an important advantage from an operational point of view with regard to a higher volumetric productivity.

\subsection{Xylose ester syntheses}

For the syntheses of xylose laurate, analysis of variance to the data of conversion after $48 \mathrm{~h}$ reaction as a function of temperature, fatty acid/xylose molar ratio, and enzymatic load showed that for the biocatalysts CALB IM (Fig. 3S, Supplementary data) and CALBSMMP-octyl (Fig. 4S, Supplementary data), none of the parameters presented statistical significance at a confidence interval of $95 \%$ (all $p$ values were less than 0.05 ). The mean conversion obtained by the model was $29.1 \%$ and $21.2 \%$, respectively. On the other hand, for the biocatalyst CALB-SMMP-octyl-glu (Fig. 5S, Supplementary data) the quadratic term for the influence of temperature showed statistical significance at a 95\% of confidence interval ( $p$ value $>0.05$ ). When only this term is considered in the regression model obtained from the factorial design, the resulting equation for the xylose conversion $(\mathrm{C}, \%)$ is:

$C(\%)=(26.34 \pm 4.45)-(11.11 \pm 4.61) \times \bar{T}^{2}$ 
In this equation, $\bar{T}$ is the codified variable related to the temperature (ranging from -1.68 to 1.68 , according to Table 1 ).

From response surfaces (Fig. 6S, Supplementary data), considering only the statistically significant factors, the maximum xylose conversion was achieved at the central point $\left(46^{\circ} \mathrm{C}\right)$. Therefore, this temperature was chosen for further syntheses in order to optimize the xylose conversion.

For the syntheses of xylose oleate, analysis of variance to the data of xylose conversion after $48 \mathrm{~h}$ reaction as a function of temperature, fatty acid/xylose molar ratio, and enzymatic load showed that for all the biocatalysts (Figs. 7S-9S, Supplementary data) the unique variable that statistically influenced the xylose conversion was the linear term related to fatty acid/xylose molar ratio. It can be observed that the effect of this variable over the xylose conversion was positive, i.e., xylose conversion linearly increases with a higher fatty acid/xylose molar ratio within the analyzed interval (see also Fig. 10S, Supplementary data).

Considering only this statistical significant variable, the resulting equations from the factorial design for the syntheses of xylose oleate catalyzed by CALB IM, CALB-SMMP-octyl-glu and CALBSMMP-octyl were, respectively:

$$
\begin{aligned}
& C(\%)=(30.58 \pm 5.46)+(12.28 \pm 5.13) \times A X R \\
& C(\%)=(19.20 \pm 2.92)+(8.43 \pm 2.74) \times A X R \\
& C(\%)=(19.92 \pm 3.48)+(8.25 \pm 3.27) \times A X R
\end{aligned}
$$

In these equations AXR is the coded variable for the fatty acid/xylose molar ratio (ranging from -1.68 to 1.68 , according to Table 1).

Hence, a linear increase in the conversion is expected for decreasing xylose concentration within the analyzed interval.

The question which remained unanswered after the factorial design was: is there a maximum conversion outside the factorial design intervals for lower xylose concentration? In this context, an analysis of the same reaction for higher fatty acid/xylose molar ratio was carried out, in order to assess whether the conversion could be increased for lower xylose concentration. Additional reactions were carried out at $46^{\circ} \mathrm{C}$ (optimum temperature), activity of $37.5 \mathrm{U}_{\mathrm{E}} / \mathrm{g}$ of fatty acid (central point of the factorial design, due to the fact that the conversion did not show to be dependent of the offered activity), and for fatty acid/xylose molar ratios of 1:0.2; 1:0.14 e 1:0.1. As shown in Fig. 3, maximum conversion was reached for fatty acid/xylose molar ratio of 1:0.2, for both fatty acids (lauric and oleic acid) and for all the biocatalysts (CALB IM, CALB-SMMP-octyl, and CALB-octyl-glu). It was previously reported that an excess of sugar increases the hydrophilicity of the microenvironment close to the enzyme due to sugar-enzyme interactions via hydrophilic groups. This hydrophilic microenvironment close to the enzyme could create problems of partitioning for the fatty acid molecules, negatively affecting the catalytic mechanism of the enzyme [22]. Besides, hygroscopic sugars may adsorb the essential water to the enzymatic activity, negatively affecting the synthesis of sugar fatty acid ester [23,24].

The xylose conversion-time profiles for the syntheses of xylose oleate and xylose laurate at predicted optimum conditions $\left(46^{\circ} \mathrm{C}\right.$, fatty acid/xylose molar ratio of 1:0.2, and activity load of $37.5 \mathrm{U}_{\mathrm{E}} / \mathrm{g}$ acid) are shown in Fig. 4, and at a higher temperature $\left(55^{\circ} \mathrm{C}\right)$ are shown in Fig. 5.

As expected, the conversions using all the immobilized biocatalysts showed the same trend, i.e., they increased up to a constant value, which depended on the temperature. For $46^{\circ} \mathrm{C}$, the final conversions were approximately $55 \%$ for all the reactions, regardless of the fatty acid or the derivative. On the other hand, the conversions were approximately $65 \%$ for all reactions at $55^{\circ} \mathrm{C}$. At the tested conditions, the derivative was not able to differentiate the molecular
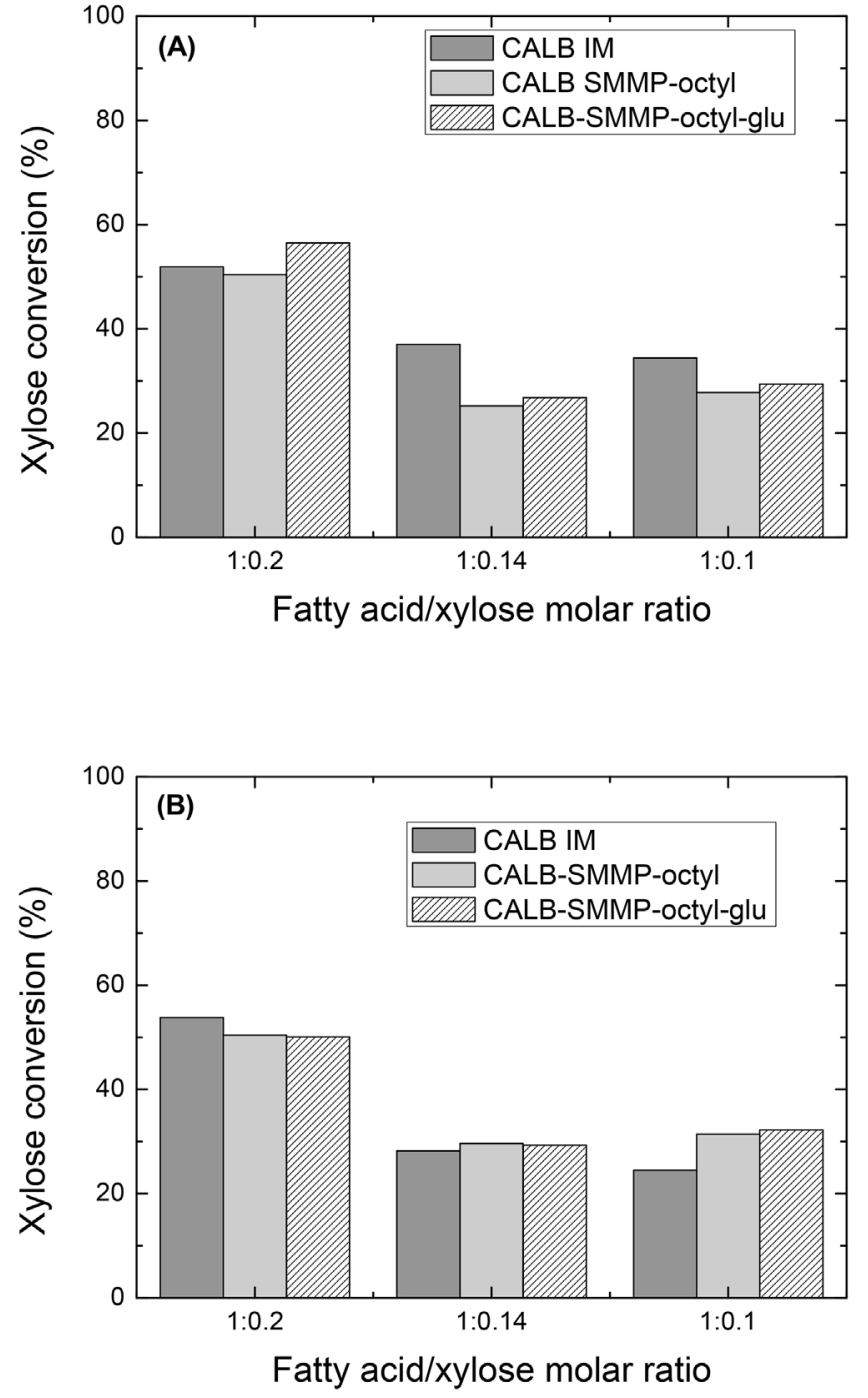

Fig. 3. Xylose conversion after $48 \mathrm{~h} v$ s. fatty acid/xylose molar ratio for the synthesis of (A) xylose oleate and (B) xylose laurate at $46^{\circ} \mathrm{C}, 300 \mathrm{rpm}, 1 \mathrm{~g}$ of molecular sieves, enzymatic load of $37.5 \mathrm{U}_{\mathrm{E}} / \mathrm{g}$ of fatty acid.

structure of these fatty acids (oleic acid is an unsaturated fatty acid, whereas lauric acid is a saturated fatty acid).

Differently from the predicted by the factorial design, the conversion for the reaction carried out at $55^{\circ} \mathrm{C}$ was higher than the conversion for $46^{\circ} \mathrm{C}$. Although the quadratic term of the temperature in the factorial design was the single statistically significant term within the analyzed interval, as discussed above, when the experimental and fitting errors are considered, this dependence might not be statistically significant, which justifies the conversion increase at higher temperatures.

The performance of the new biocatalysts of CALB immobilized on SMMPs was similar to the most popular one (Novozym 435) regardless of the reactional conditions. As reported by Abdulmalek et al. [14], the conversion in the synthesis of xylose caproate catalyzed by Novozym 435 (immobilized Candida antarctica B) at $60^{\circ} \mathrm{C}$ ranged from 50 to $64 \%$ (depending on the solvent system) after $24 \mathrm{~h}$ reaction. Bidjou-Haiour and Klai [13] also reported the synthesis of xylose laurate catalyzed by Novozym 435 . The reaction achieved $65 \%$ conversion at $60^{\circ} \mathrm{C}$ after $48 \mathrm{~h}$ using ethyl methyl ketone as cosolvent. Higher conversions for the synthesis of xylose fatty acid esters were previously reported using xylose acetals. Xylose fatty acid esters were synthesized by the reaction between 1,2-Oisopropylidene-D-xylofuranose and different fatty acids (lauric and 

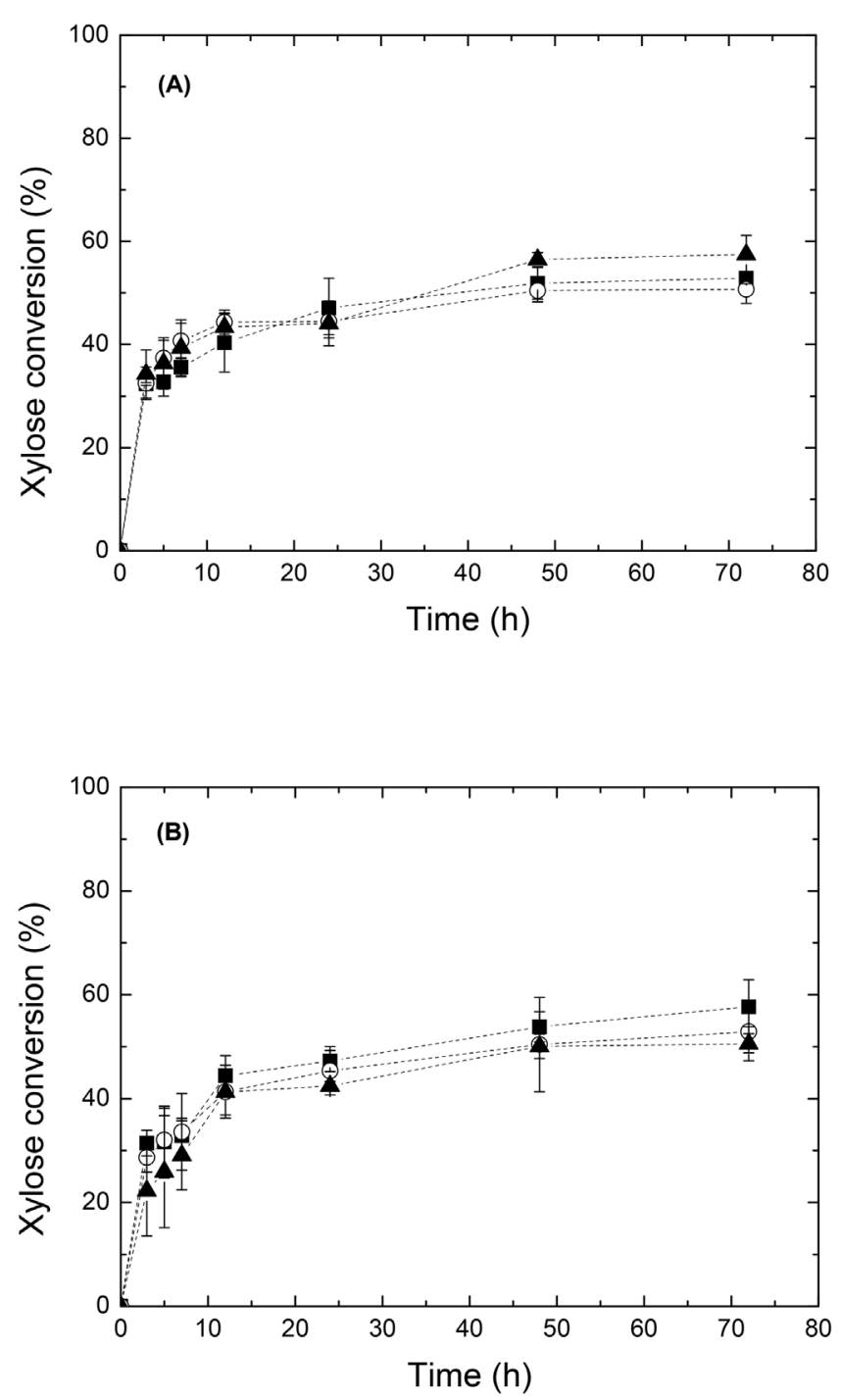

Fig. 4. Xylose conversion-time profiles for the synthesis of (A) xylose oleate and (B) xylose laurate at $46^{\circ} \mathrm{C}, 300 \mathrm{rpm}, 20 \mathrm{mM}$ xylose, $1 \mathrm{~g}$ of molecular sieves, using CALB $\operatorname{IM}(\boldsymbol{\square})$, CALB-SMMP-octyl ( $\bigcirc)$ e CALB-SMMP-octyl-glu ( $\Delta$ ). Activity load of $37.5 \mathrm{U}_{\mathrm{E}} / \mathrm{g}$ acid.

stearic acids), catalyzed by lipase from Mucor mieihei (Lipozyme IM-60), followed by deacetalization in order to remove the isopropylidene group [15]. Yields around $80 \%$ were obtained before the deacetalization. Overall yields were reduced to around $60 \%$ after deacetalization due to the purification process itself. The xylose acetal was also used by Ward et al. [16] for the synthesis of different xylose fatty acid esters (lauric, myristic, palmitic, stearic, arachidic, behenic, oleic, and arachidonic acids and a polyunsaturated fatty acid concentrate from cod liver oil). Six different commercial lipases were compared in the reaction and the commercial Novozym 435 presented the better results. Maximum conversions around $80 \%$ were obtained after $12 \mathrm{~h}$, when lauric acid was used as acyl donor. Possibly, the reason for higher conversions reported in these studies is related to the use of xylose acetals instead of xylose itself (as used in this work), which possibly improves the esterification reaction by protecting hydroxyl groups from positions 1 and 2 of the xylose molecule. Nonetheless, this process is laborious and increases the cost of the ester production. Thus, an economic analysis of both processes (xylose or xylose acetals as acyl acceptor) should be led to verify their industrial feasibility.
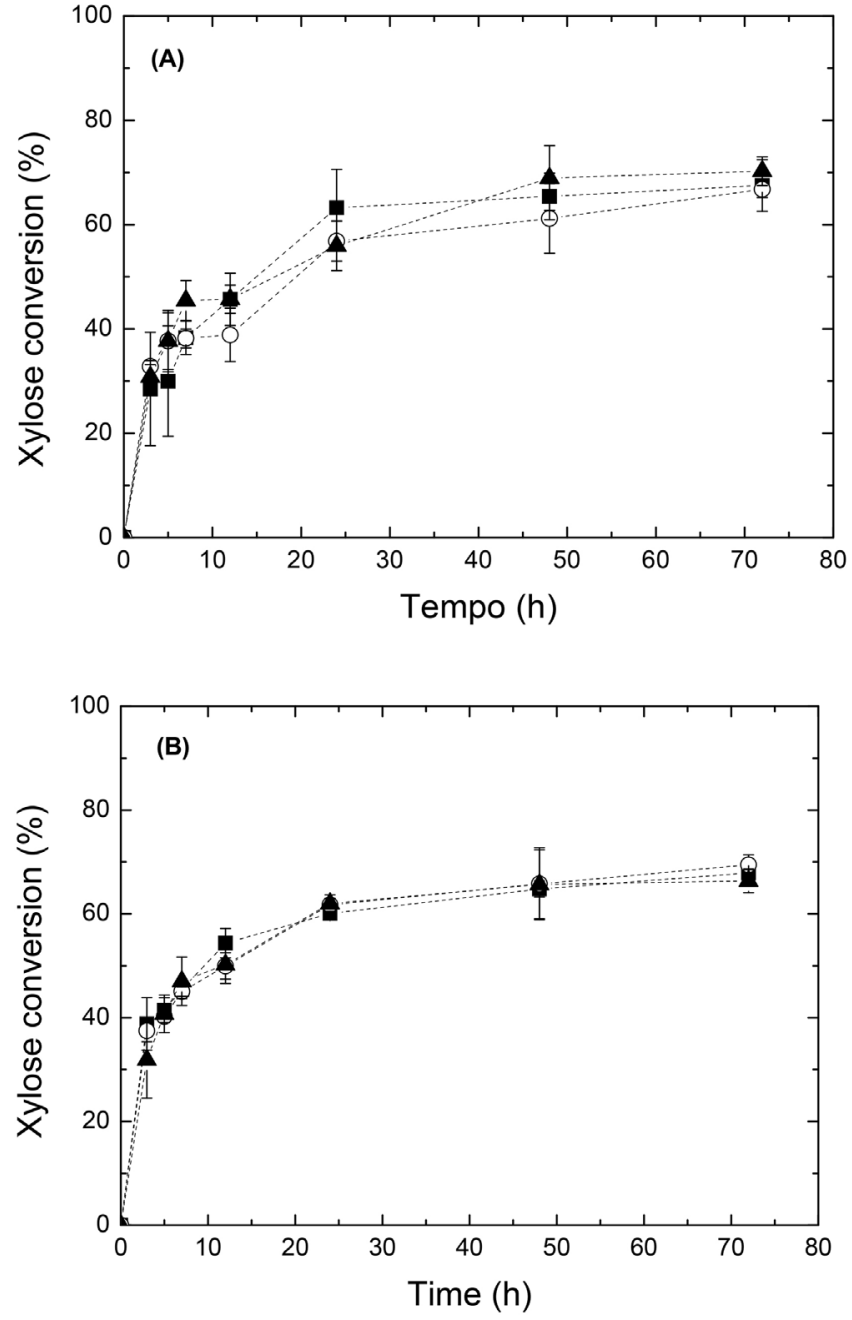

Fig. 5. Xylose conversion-time profiles for the synthesis of (a) xylose oleate and (b) xylose laurate at $55^{\circ} \mathrm{C}, 300 \mathrm{rpm}, 20 \mathrm{mM}$ xylose, $1 \mathrm{~g}$ of molecular sieves, using CALB IM ( $\mathbf{\square})$, CALB-SMMP-octyl ( $\bigcirc$ ) e CALB-SMMP-octyl-glu ( $\mathbf{\Delta}$ ). Activity load of $37.5 \mathrm{U}_{\mathrm{E}} / \mathrm{g}$ acid.

\subsection{Operational stability}

Fig. 6 shows the reuse assays for the biocatalysts CALB-SMMPoctyl, CALB-SMMP-octyl-glu and CALB IM for 48 h-batches of syntheses of xylose oleate and laurate at $46^{\circ} \mathrm{C}$.

All biocatalysts, regardless of the immobilization mechanisms and physical and chemical nature of the supports, presented similar operational stability in the synthesis of xylose fatty esters, remaining actives after ten $48 \mathrm{~h}$-cycles. Regardless of the chemistry linking CALB and support (adsorption or covalent linkages) the biocatalysts were very suitable to be used in a medium with very low water concentration. SMMP-octyl and SMMP-octyl-glu showed to be competitive supports compared to commercial organic resins, because SMMPs can be easily recovered from a viscous and complex medium (i.e., containing insoluble sugars and molecular sieves, as in the case of SFAEs synthesis), reused, and regenerated by calcination to be again activated and to be used for immobilization of fresh enzyme [6].

\section{Conclusions}

Silica magnetic microparticles chemically modified with octyl and octyl plus glutaraldehyde groups showed to be promising carriers with magnetic properties for enzyme immobilization. The 

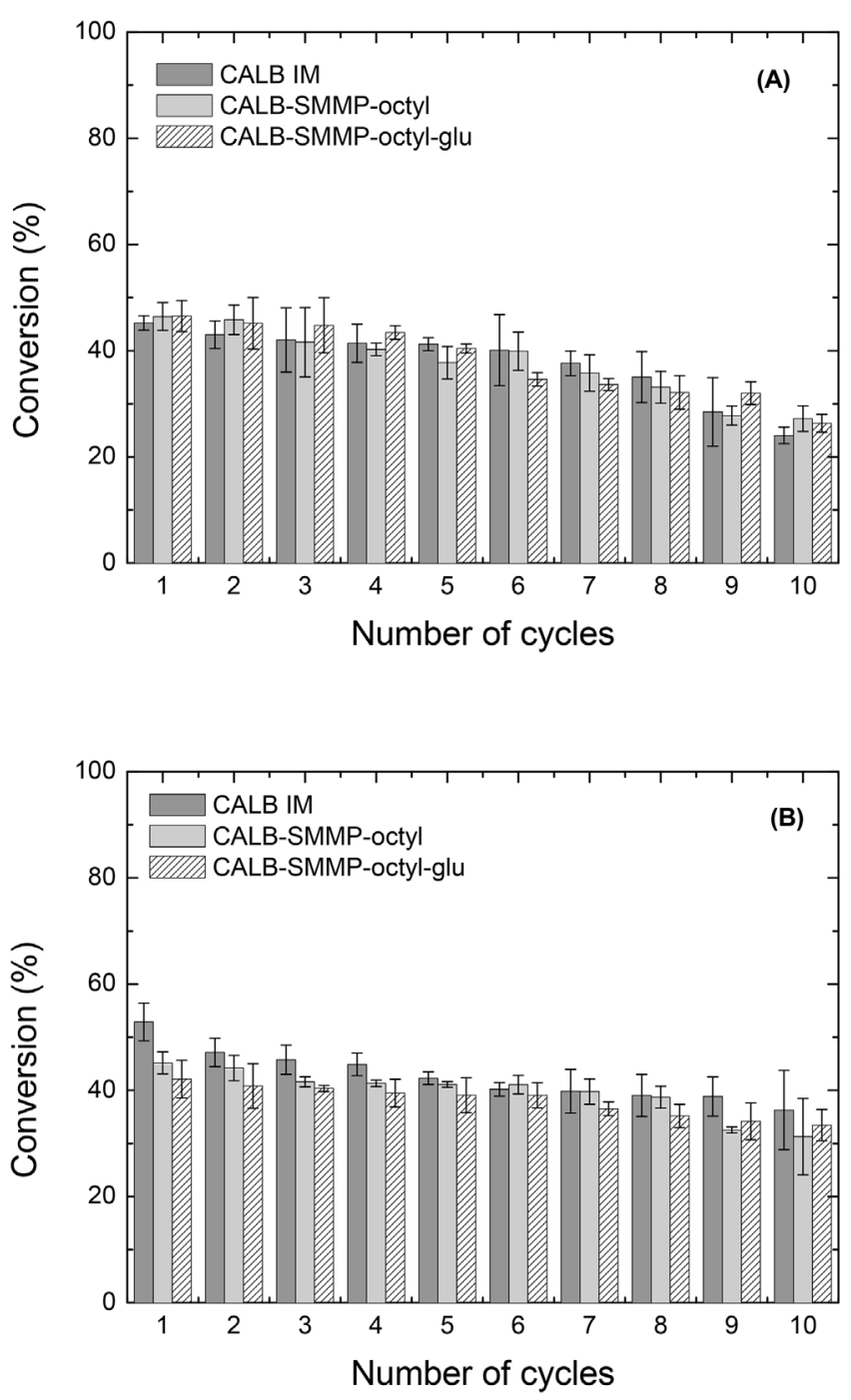

Fig. 6. Conversion vs. number of cycles for the synthesis of $(A)$ xylose oleate and (B) xylose laurate at $46^{\circ} \mathrm{C}, 300 \mathrm{rpm}, 20 \mathrm{mM}$ xylose, $1 \mathrm{~g}$ of molecular sieves, using CALB IM (gray columns), CALB-SMMP-octyl (light gray columns) e CALB-SMMP-octyl-glu (white columns). Activity load of $37.5 \mathrm{U}_{\mathrm{E}} / \mathrm{g}$ fatty acid.

immobilization of an industrially important lipase (CALB) on these supports was successfully used to prepare active and stable biocatalysts for the synthesis of xylose fatty acid esters. Under optimized conditions, xylose oleate and laurate were prepared with xylose conversions up to $65 \%$. The biocatalysts prepared were competitive to the commercial ones, with better properties for a rapid and ease recovery from a complex reaction medium.

\section{Funding}

This work was supported by the São Paulo Research Foundation (FAPESP) [ grant \#2012/24277-9].

\section{Acknowledgments}

The authors thank the Brazilian Foundations FAPESP, CNPq and CAPES for financial support.

\section{Appendix A. Supplementary data}

Supplementary data associated with this article can be found, in the online version, at http://dx.doi.org/10.1016/j.molcatb.2017.04. 002 .

\section{References}

[1] V. Vescovi, W. Kopp, J.M. Guisán, R.L.C. Giordano, A.A. Mendes, P.W. Tardioli, Improved catalytic properties of Candida antarctica lipase B multi-attached on tailor-made hydrophobic silica containing octyl and multifunctional amino- glutaraldehyde spacer arms, Process Biochem. 51 (2016) 2055-2066, http://dx.doi.org/10.1016/j.procbio.2016.09.016.

[2] L.N. Lima, G.C. Oliveira, M.J. Rojas, H.F. Castro, P.C.M. Da Rós, A.A. Mendes, et al., Immobilization of Pseudomonas fluorescens lipase on hydrophobic supports and application in biodiesel synthesis by transesterification of vegetable oils in solvent-free systems, J. Ind. Microbiol. Biotechnol. 42 (2015) 523-535, http://dx.doi.org/10.1007/s10295-015-1586-9.

[3] V. Vescovi, R.L.C. Giordano, A.A. Mendes, P.W. Tardioli, Immobilized lipases on functionalized silica particles as potential biocatalysts for the synthesis of fructose oleate in an organic Solvent/Water system, Molecules 22 (2017) 212. http://dx.doi.org/10.3390/molecules22020212.

[4] M. Kalantari, M. Kazemeini, A. Arpanaei, Evaluation of biodiesel production using lipase immobilized on magnetic silica nanocomposite particles of various structures, Biochem. Eng. J. 79 (2013) 267-273, http://dx.doi.org/10. 1016/j.bej.2013.09.001.

[5] M. Khoobi, S.F. Motevalizadeh, Z. Asadgol, H. Forootanfar, A. Shafiee, M.A. Faramarzi, Polyethyleneimine-modified superparamagnetic Fe3O4 nanoparticles for lipase immobilization: characterization and application, Mater. Chem. Phys. 149 (2015) 77-86, http://dx.doi.org/10.1016/j. matchemphys.2014.09.039.

[6] W. Kopp, F.A. Silva, L.N. Lima, S.H. Masunaga, P.W. Tardioli, R.C. Giordano, et al., Synthesis and characterization of robust magnetic carriers for bioprocess applications, Mater. Sci. Eng. B 193 (2015) 217-228, http://dx.doi. $\operatorname{org} / 10.1016 / j . m s e b .2014 .12 .002$.

[7] A.M. Gumel, M.S.M. Annuar, T. Heidelberg, Y. Chisti, Lipase mediated synthesis of sugar fatty acid esters, Process Biochem. 46 (2011) 2079-2090, http://dx.doi.org/10.1016/j.procbio.2011.07.021.

[8] M. Ferrer, J. Soliveri, F.J. Plou, N. López-Cortés, D. Reyes-Duarte, M. Christensen, et al., Synthesis of sugar esters in solvent mixtures by lipases from Thermomyces lanuginosus and Candida antarctica B, and their antimicrobial properties, Enzyme Microb. Technol. 36 (2005) 391-398, http:// dx.doi.org/10.1016/j.enzmictec.2004.02.009.

[9] M. Habulin, S. Šabeder, Ž. Knez, Enzymatic synthesis of sugar fatty acid esters in organic solvent and in supercritical carbon dioxide and their antimicrobial activity, J. Supercrit. Fluids 45 (2008) 338-345, http://dx.doi.org/10.1016/j. supflu.2008.01.002.

[10] T. Kobayashi, Lipase-catalyzed syntheses of sugar esters in non-aqueous media, Biotechnol. Lett. 33 (2011) 1911-1919, http://dx.doi.org/10.1007/ s10529-011-0663-z.

[11] S. Adachi, T. Kobayashi, Synthesis of esters by immobilized-lipase-catalyzed condensation reaction of sugars and fatty acids in water-miscible organic solvent, J. Biosci. Bioeng. 99 (2005) 87-94, http://dx.doi.org/10.1263/jbb.99. 87.

[12] S.W. Chang, J.F. Shaw, Biocatalysis for the production of carbohydrate esters, N. Biotechnol. 26 (2009) 109-116, http://dx.doi.org/10.1016/j.nbt.2009.07. 003.

[13] C. Bidjou-Haiour, N. Klai, Lipase catalyzed synthesis of fatty acid xylose esters and their surfactant properties, Asian J. Chem. 25 (2013) 4347-4350.

[14] E. Abdulmalek, N.F. Hamidon, M.B. Abdul Rahman, Optimization and characterization of lipase catalysed synthesis of xylose caproate ester in organic solvents, J. Mol. Catal. B Enzym. 132 (2016) 1-4, http://dx.doi.org/10. 1016/j.molcatb.2016.06.010.

[15] G. Fregapane, D.B. Sarney, S.G. Greenberg, D.J. Knight, E.N. Vulfson, Enzymatic synthesis of monosaccharide fatty acid esters and their comparison with conventional products, J. Am. Oil Chem. Soc. 71 (1994) 87-91, http://dx.doi. org/10.1007/BF02541477.

[16] O.P. Ward, J. Fang, Z. Li, Lipase-catalyzed synthesis of a sugar ester containing arachidonic acid, Enzyme Microb. Technol. 20 (1997) 52-56, http://dx.doi. org/10.1016/S0141-0229(96)00081-6.

[17] R.M. Blanco, P. Terreros, N. Muñoz, E. Serra, Ethanol improves lipase immobilization on a hydrophobic support, J. Mol. Catal. B Enzym. 47 (2007) 13-20, http://dx.doi.org/10.1016/j.molcatb.2007.03.003.

[18] F. Beisson, A. Tiss, C. Riviere, R. Verger, Methods for lipase detection and assay: a critical review, Eur. J. Lipid Sci. Technol. 102 (2000) 133-153, http://dx.doi. org/10.1002/(SICI)1438-9312(200002)102:2<133:AID-EJLT133>3.0.CO;2-X.

[19] A.V. Paula, A.B.R. Moreira, L.P. Braga, H.F. de Castro, L.M. Bruno, Comparação do desempenho da lipase de candida rugosa imobilizada em suporte híbrido de polissiloxano-polivinilálcool empregando diferentes metodologias, Quim. Nova. 31 (2008) 35-40, http://dx.doi.org/10.1590/S010040422008000100007.

[20] L. Betancor, F. López-Gallego, A. Hidalgo, N. Alonso-Morales, G.D.-O.C. Mateo, R. Fernández-Lafuente, et al., Different mechanisms of protein immobilization on glutaraldehyde activated supports: effect of support activation and 
immobilization conditions, Enzyme Microb. Technol. 39 (2006) 877-882, http://dx.doi.org/10.1016/j.enzmictec.2006.01.014.

[21] D.C. Vieira, L.N. Lima, A.A. Mendes, W.S. Adriano, R.C. Giordano, R.L.C. Giordano, et al., Hydrolysis of lactose in whole milk catalyzed by $\beta$-galactosidase from Kluyveromyces fragilis immobilized on chitosan-based matrix, Biochem. Eng. J. 81 (2013) 54-64, http://dx.doi.org/10.1016/j.bej. 2013.10.007.

[22] Y. Yan, U.T. Bornscheuer, G. Stadler, S. Lutz-Wahl, M. Reuss, R.D. Schmid, Production of sugar fatty acid estrs by enzymatic esterification in a stirred-tank membrane reactor: optimization of parameters by response surface methodology, J. Am. Oil Chem. Soc. 78 (2001) 147-153, http://dx.doi. org/10.1007/s11746-001-0235-X.
[23] S. Tarahomjoo, I. Alemzadeh, Surfactant production by an enzymatic method, Enzyme Microb. Technol. 33 (2003) 33-37, http://dx.doi.org/10.1016/S01410229(03)00085-1.

[24] D. Coulon, A. Ismail, M. Girardin, B. Rovel, M. Ghoul, Effect of different biochemical parameters on the enzymatic synthesis of fructose oleate, J. Biotechnol. 51 (1996) 115-121, http://dx.doi.org/10.1016/01681656(96)01588-X. 